УДК 630*.865.1+661.183.123.2

\title{
СОРБЦИОННЫЕ СВОЙСТВА КАТИОНИТОВ, ПОЛУЧЕННЫХ ОБРАБОТКОЙ ЕЛОВЫХ ОПИЛОК РАСТВОРАМИ СЕРНОЙ КИСЛОТЫ
}

\author{
(ㄱ) И.П. Дейнеко*, А.Н. Симонова
}

\author{
Санкт-Петербургский государственный технологический университет \\ растительных полимеров, ул. Ивана Черных, 4, Санкт-Петербург, 198095 \\ (Россия), e-mail: ipdeineko@mail.ru
}

\begin{abstract}
Предложен процесс получения катионитов из древесного сырья, заключающийся в термообработке под вакуумом древесных опилок, предварительно пропитанных водным раствором серной кислоты, с одновременной отгонкой избыточной и реакционной воды. Целевой продукт (выход - 66-68\%) представляет собой полифункциональный катионит, содержащий сильнокислотные и слабокислотные группы. Исследовано влияние концентрации серной кислоты, использованной для пропитки опилок, в диапазоне 4,4-56,0\% на ионообменные свойства получаемых катионитов. Содержание кислотных групп в катионите с повышением концентрации кислоты возрастает и при концентрации 56\% достигает 4,6 ммоль/г. Изучена сорбция катионитами ионов тяжелых металлов. Установлена высокая емкость ионизированной формы сорбентов к названным катионам. Максимальная емкость к элементам у сорбентов в ионизированном состоянии возрастает в последовательности (ммоль/г): $\mathrm{Ni}(1,71)>\mathrm{Co}(1,78)>\mathrm{Cu}(1,83)>\mathrm{Pb}(2,16)$.

Ключевые слова: еловые опилки, серная кислота, катиониты, обменная емкость, кислотные группы, сорбция, свинец, кобальт, никель, медь.
\end{abstract}

\section{Введение}

Нарастание экологических проблем, связанное в значительной степени с усиливающимся загрязнением гидросферы, диктует необходимость совершенствования процессов очистки водных систем [1]. Особенно большую опасность для живых организмов представляют попадающие из различных источников в природные водоемы ионы токсичных тяжелых металлов [2].

Одним из наиболее эффективных подходов к очистке загрязненных водных стоков является использование сорбционных процессов. Для удаления ионов из разбавленных растворов применяются синтетические ионообменные смолы (иониты), сорбционная емкость которых по отношению к тяжелым металлам лежит в диапазоне 2-5 мэкв/г [3]. Однако широкое распространение ионитов сдерживается относительно высокой их стоимостью [4].

Поэтому большое значение имеют работы, направленные на создание недорогих эффективных сорбентов. В последние годы проявляется большой интерес к получению ионообменных сорбентов на основе возобновляемого лигноцеллюлозного сырья [5, 6], в частности древесных отходов [5-8].

Использование непосредственно древесины и ее компонентов в качестве ионообменников является нецелесообразным вследствие низкого содержания в структурных составляющих клеточных стенок (полисахаридах и лигнине) ионогенных группировок [9]. Обменная емкость древесных опилок по катионам металлов очень мала и не превышает 0,1 мэкв/г [7, 11]. Поэтому проводятся интенсивные исследования по повышению содержания в лигноцеллюлозных материалах активных центров посредством химического модифицирования сырья $[10,11]$. Перспективным способом модифицирования может быть обработка дре-

Дейнеко Иван Павлович - профессор, доктор химических наук, e-mail: ipdeineko@mail.ru

Симонова Александра Николаевна - студентка весины кислотными реагентами. В частности, имеются данные, что действием серной кислоты высокой концентрации на древесинное вещество

\footnotetext{
* Автор, с которым следует вести переписку.
} 
при температуре около $85{ }^{\circ} \mathrm{C}$ удается получать катиониты, обменная емкость которых достигает 5 мэкв/г [12]. Однако при использовании концентрированных растворов кислоты задействуется большое количество реагента (расход более $200 \%$ относительно исходного сырья), и образуется значительное количество трудно утилизируемых отходов. При использовании же разбавленных растворов кислот, обеспечивающих малый расход реагента, выход и обменная емкость получаемых сорбентов оказываются невысокими (обменная емкость - менее 0,5 мэкв/г) [5-7].

Для устранения отмеченных недостатков нами разрабатывается процесс, в котором для получения катионитов предлагается обработка сырья разбавленным раствором серной кислоты, концентрация которой в ходе процесса повышается за счет отгонки избыточной и реакционной воды [13-15]. Применение разбавленных растворов позволяет значительно снизить расход кислотного реагента.

Поскольку отгонка основной массы воды проходит на начальной стадии обработки, большую часть времени процесс протекает в безводной среде, т.е. в среде концентрированной серной кислоты. Результатом этого является существенное снижение роли реакций деструкции и усиление вклада реакций конденсации, обеспечивающих высокий выход катионита. В ходе процесса в продукте происходит образование ионогенных группировок, включающих как сильнокислотные (сульфоновокислые), так и слабокислотные (карбоксильные, енольные) группы [15]. При этом содержание ионогенных групп (3-7 мэкв/г) [13, 14 ] сравнимо с содержанием этих групп в синтетических катионитах. Присутствие в получаемых сорбентах слабокислотных групп, обладающих комплексообразующими свойствами, указывает на возможность применения получаемых катионитов в качестве эффективных сорбентов для удаления из растворов ионов тяжелых металлов [16].

В настоящей статье рассмотрены результаты исследования влияния расхода серной кислоты на выход и обменную емкость катионитов, полученных кислотно-каталитическим модифицированием еловых опилок, а также изучена сорбция этими сорбентами катионов тяжелых металлов.

\section{Экспериментальная часть}

Эксперименты выполнялись в соответствии с предложенной ранее схемой $[14,15]$, приведенной на рисунке 1.

Исходным сырьем в опытах служили еловые опилки (фракция 0,5-1,0 мм). В качестве реакционной среды использовали водные растворы серной кислоты различной концентрации.

Навеску воздушно сухих опилок (около 6 г) заливали водным раствором кислоты и после пропитки сырья (60 мин) избыток раствора отделяли на вакуум-фильтре. Затем пропитанные кислотой опилки переносили в предварительно взвешенную круглодонную двугорлую колбу (объем $-250 \mathrm{~cm}^{3}$ ) и находили массу пропитанных опилок. На основании полученных данных рассчитывали массу раствора, пропитывающего опилки и, соответственно, количество серной кислоты, отнесенное к массе исходного сырья (расход, G, \%) по следующей формуле:

$$
G=\frac{c\left(m_{1}-m_{0}\right)}{m_{0} K_{S}}
$$

где $c$ - концентрация серной кислоты, использованной для пропитки образца, масс. \%; $m_{l}-$ масса пропитанных кислотой опилок, г; $m_{0}$ - масса воздушно-сухих опилок, г; $K_{S}$ - коэффициент сухости воздушносухих опилок.

Данные по концентрации серной кислоты, использованной для пропитки образцов, и по расходу реагента в каждом опыте приведены в таблице.

Реакционная колба была снабжена термометром и насадкой с капилляром. Термометр помещали в колбе таким образом, чтобы его ртутный шарик был полностью погружен в сырье. Проходящий через капилляр воздух предварительно пропускался через свернутую в спираль трубку $(100 \times 0,2$ см), помещенную в трубчатую печь с температурой $350{ }^{\circ} \mathrm{C}$. Эксперименты проводили на обычной перегонной установке, подсоединенной к водоструйному насосу с использованием в качестве приемника калиброванную пробирку для контроля количества отогнанной воды. 
Рис. 1. Общая схема проведения

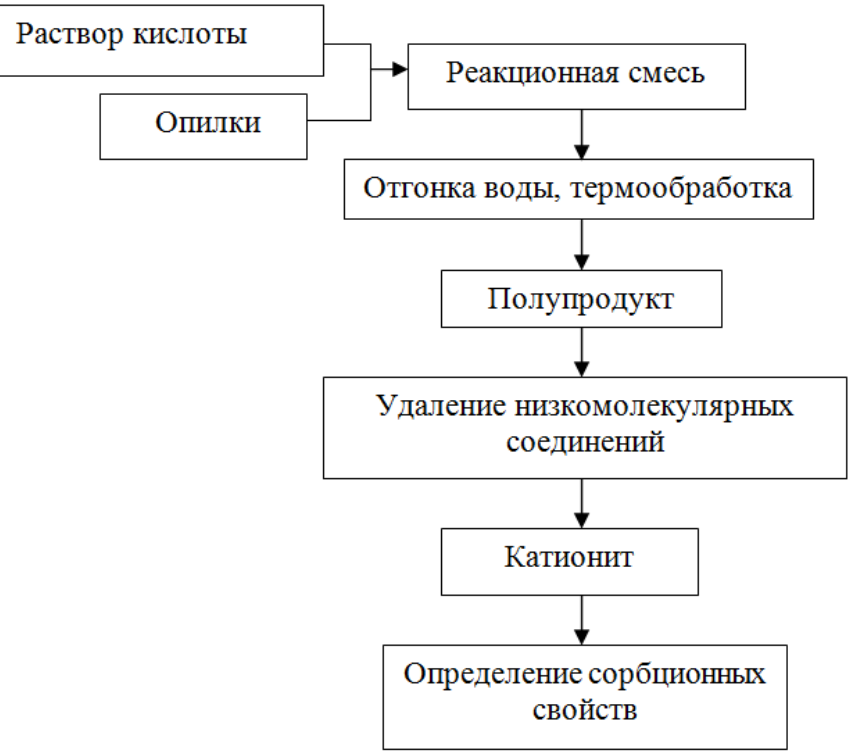

эксперимента

Начальная концентрация и расход серной кислоты

\begin{tabular}{l|c|c|c|c|c|c|c}
\hline $\mathrm{H}_{2} \mathrm{SO}_{4}$ & 1 & 2 & 3 & 4 & 5 & 6 & 7 \\
\hline Концентрация, \% & 4,4 & 6,7 & 14,3 & 19,0 & 26,5 & 39,1 & 56,0 \\
\hline Расход, \% & 7,01 & 11,7 & 21,3 & 31,3 & 50,0 & 80,8 & 188 \\
\hline
\end{tabular}

Нагрев реакционной смеси осуществляли с помощью глицериновой бани. Температуру бани во всех опытах поддерживали $140{ }^{\circ} \mathrm{C}$; выход на режим составлял 40-50 мин при общей продолжительности процесса 3 ч. В связи с низким расходом проходящего через капилляр и выполняющего роль теплоносителя воздуха максимальная температура реакционной смеси в отдельных экспериментах в месте ее измерения в массе сырья не была одинаковой; при повышении начальной концентрации серной кислоты она увеличивалась от $107^{\circ} \mathrm{C}$ в опыте 1 до $122^{\circ} \mathrm{C}$ в опыте 7 . Остаточное давление в системе колебалось в интервале 30-50 мм ртутного столба.

По завершении процесса реакционную колбу охлаждали, полученный темноокрашенный мелкодисперсный материал, сохраняющий форму опилок, отмывали от непрореагировавшей серной кислоты водой и после сушки в вакуум-эксикаторе определяли выход полупродукта.

Для получения целевого продукта (катионита) полупродукт обрабатывали 5\%-ным раствором гидроксида натрия до обесцвечивания промывных вод. Затем, после отмывки продукта от избытка щелочи водой, катионит переводили в $\mathrm{H}^{+}$-форму, обрабатывая 5\%-ным раствором соляной кислоты и в заключение промывали водой до нейтральной реакции элюата. Полученный катионит высушивали в вакуумэксикаторе над гранулированным гидроксидом натрия и определяли выход. Разность между выходами полупродукта и катионита представляла собой количество растворимых в щелочной среде веществ.

Установление ионообменной емкости катионитов осуществляли, определяя в образцах содержание сильнокислотных и слабокислотных групп динамическим методом [15].

Для изучения сорбционных свойств катионитов готовились 0,1 М растворы нитратов следующих металлов: $\mathrm{Pb}^{2+}, \mathrm{Co}^{2+}, \mathrm{Ni}^{2+}, \mathrm{Cu}^{2+}$, для чего использовались препараты солей квалификации «чда». Содержание катионов в растворах определяли титриметрическим методом, беря за основу стандартные методики $[17,18]$.

В колбу помещали 0,3-0,6 г сорбента (Н- или Na-форму), предварительно высушенного в вакуумэксикаторе над гранулированным гидроксидом натрия до постоянной массы, и пропитывали образец 10 см$^{3}$ дистиллированной воды в течение 2 ч. После набухания в колбу добавляли $50 \mathrm{~cm}^{3} 0,1 \mathrm{M}$ раствора соли тяжелого металла и выдерживали образец сутки в растворе, периодически перемешивая смесь. Затем раствор отделяли от катионита с помощью пористого стеклянного фильтра. Количество сорбированных ионов металлов находили по разности между концентрацией ионов в исходном растворе и в растворе (фильтрате), полученном после взаимодействия с сорбентом. При титровании исходного раствора к нему добавляли воду с таким расчетом, чтобы соблюдалось соотношение, как и при анализе образцов, - 5 : 1. 
Анализ растворов на катионы $\mathrm{Pb}^{2+}, \mathrm{Co}^{2+}, \mathrm{Ni}^{2+}$ выполняли с использованием в качестве титранта 0,05 М раствор ЭДТА:

А) определение концентрации ионов $\mathrm{Pb}^{2+}$ и $\mathrm{Co}^{2+}$ в растворах проводили по одной методике: в аликвотную часть $\left(5 \mathrm{~cm}^{3}\right)$ анализируемого раствора добавляли $5 \mathrm{~cm}^{3}$ дистиллированной воды, $3 \mathrm{~cm}^{3}$ ацетатного буферного раствора, $1 \mathrm{~cm}^{3}$ индикатора ксиленолового оранжевого (0,1\%-ный водный раствор) и титровали 0,05 М раствором ЭДТА до перехода малиновой окраски индикатора в лимонно-желтую;

Б) при определении концентрации ионов $\mathrm{Ni}^{2+}$ в аликвотную пробу раствора приливали 10 мл воды, 5 мл аммонийного буфера и добавляли 5-7 мг мурексида растертого с хлоридом натрия (1: 100); титрование 0,05 М раствором ЭДТА осуществляли до перехода желтой окраски раствора в фиолетовую;

В) определение концентрации ионов $\mathrm{Cu}^{2+}$ в растворах проводили следующим образом: в аликвотную часть $\left(5 \mathrm{~cm}^{3}\right)$ анализируемого раствора разбавляли $5 \mathrm{~cm}^{3}$ дистиллированной воды, добавляли $3 \mathrm{~cm}^{3} 10 \%$ иодида калия и титровали $0,05 \mathrm{M}$ раствором тиосульфата натрия (к концу титрования прибавляя $1 \mathrm{~cm}^{3} 0,5 \%$ раствора крахмала) до исчезновения темной окраски.

Расчет концентрации катионов тяжелых металлов (ммоль/г) проводился по следующей формуле:

$$
E_{C d}=\frac{\left(V^{O}-V^{A}\right) V_{O} X}{V_{A} m}
$$

где $V^{O}$ - объем раствора титранта $\left(\mathrm{cm}^{3}\right)$, пошедший на титрование аликвотной части исходного раствора; $V^{A}$ - объем раствора титранта $\left(\mathrm{cm}^{3}\right)$, пошедший на титрование аликвотной части фильтрата, полученного после взаимодействия с катионитом; $V_{O}$ - суммарный объем $\left(\right.$ см$\left.^{3}\right)$ раствора соли и дистиллированной воды, использованной для набухания катионита; $V_{A}$ - объем аликвотной части анализируемого раствора $\left(\mathrm{cm}^{3}\right)$; $m$ - масса навески катионита (г); $X$ - концентрация раствора титранта, ммоль $/ \mathrm{cm}^{3}$.

При определении емкости сорбентов в натриевой форме количественные данные пересчитывали на $\mathrm{H}^{+}$-форму.

\section{Обсуждение результатов}

Как отмечалось во введении, предлагаемый способ получения катионитов из древесного сырья осуществляется с использованием для обработки опилок водных растворов серной кислоты. Принципиальным отличием от известных способов [5-12] является включение в процесс стадии отгонки избыточной и реакционной воды, которая вследствие проведения процесса под вакуумом осуществляется и завершается при подъеме температуры. Одним из важнейших параметров процесса является концентрация кислоты, использованной для пропитки опилок (начальная концентрация). Однако в связи с тем, что основная часть процесса протекает практически в безводной среде, влияние начальной концентрации кислоты на свойства продукта является опосредованным, так как основным фактором оказывается количество кислоты в реакционной среде (расход реагента), которое и определяется концентрацией кислоты, использованной для пропитки. Соответственно, расход реагента в расчете на исходное сырье в проведенных опытах возрастал от 7 до $188 \%$ (см. табл.).

Выбор температуры процесса $\left(140{ }^{\circ} \mathrm{C}\right)$ основывался на результатах предыдущих исследований, выполненных с использованием азеотропной отгонки воды, которые показали, что наиболее высокая обменная емкость характерна для сорбентов, полученных в интервале температур $125-150{ }^{\circ} \mathrm{C}$ [13].

Представленные на рисунке 2 результаты настоящего исследования показывают, что выход катионита при разной концентрации и, соответственно, разном расходе кислотного реагента изменяется в сравнительно узких пределах (65,6-69,6\%).

Более существенное влияние концентрация и расход кислоты оказывают на выход полупродукта. При использовании раствора кислоты относительно небольшой концентрации выход полупродукта весьма значителен (более 80\%). По мере повышения концентрации реагента в растворе выход полупродукта снижается. Полупродукт, как отмечалось, в отличие от целевого продукта (катионита), содержит растворимые в щелочном растворе вещества, т.е. вещества, имеющие относительно невысокую молекулярную массу. Их образование происходит в результате гидролитической деструкции полимерных компонентов древесины (преимущественно легкогидролизуемых полисахаридов), протекающих с участием молекул воды. По- 
скольку при низкой концентрации кислоты в растворе доля воды в реакционной смеси весьма значительна и ее удаление происходит в течение более длительного времени, чем в случае использования растворов кислоты повышенной концентрации, реакции деструкции в присутствии большего количества воды в системе получают достаточно сильное развитие. В связи с тем, что образование низкомолекулярных примесей отражается на выходе и свойствах целевого продукта, приведенные результаты позволяют сделать вывод, что для получения сорбентов желательно использование растворов кислоты с концентрацией не менее $15 \%$. С другой стороны, наибольший выход целевого продукта наблюдается при начальной концентрации реагента 26 и 39\%, и поэтому применение растворов серной кислоты с концентрацией более 40\% также можно считать нецелесообразным. Здесь уместно отметить, что реальный расход кислоты на процесс может быть существенно меньшим, так как значительную часть реагента после отмывки целевого продукта от избытка кислоты можно использовать для пропитки следующей партии сырья.

Наиболее важной характеристикой катионообменных сорбентов является их ионообменная емкость. Результаты исследования подтвердили полученные ранее данные о том, что при кислотной обработке лигноцеллюлозных материалов получаются полифункциональные катиониты [13-15]. В состав сорбентов входят как сильнокислотные, так и слабокислотные функциональные группы. Приведенные на рисунке 3 результаты исследования показывают, что наибольший вклад в ионообменные свойства полученных катионитов вносят слабокислотные ионогенные центры, представленные примерно в одинаковой степени карбоксильными и енольными (в том числе и фенольными) функциональными группами.

Относительно низкое содержание в получаемых сорбентах сильнокислотных групп, представляющих собой очевидно сульфоновокислые группы, можно объяснить участием способных сульфироваться реакционных центров лигноуглеводного комплекса в конкурентных реакциях конденсации, вследствие чего вероятность протекания реакций сульфирования снижается.

Сильное влияние на накопление ионогенных центров оказывает расход серной кислоты. С повышением расхода кислоты содержание в сорбентах всех кислотных групп существенно возрастает. Суммарное содержание кислотных групп в сорбентах повышается от 2,3 ммоль/г в опыте с низким расходом (7,0\%) кислотного реагента до 4,6 ммоль/г в опыте с высоким расходом (188\%) серной кислоты. Однако наиболее сильное увеличение кислотных групп в сорбентах происходит при повышении расхода от 7,0 до $81 \%$ или увеличении концентрации реагента в растворе от 4,4 до 39\%. Это обосновывает сделанный выше вывод о нецелесообразности использования в процессе обработки опилок растворов кислоты более высокой концентрации.

Присутствие в полученных сорбентах большого количества полярных кислотных групп, проявляющих электронодонорные свойства, свидетельствует о возможности их участия в образовании координационных связей [16]. Поэтому может быть весьма перспективным использование этих материалов в качестве сорбентов для сорбции тяжелых металлов.

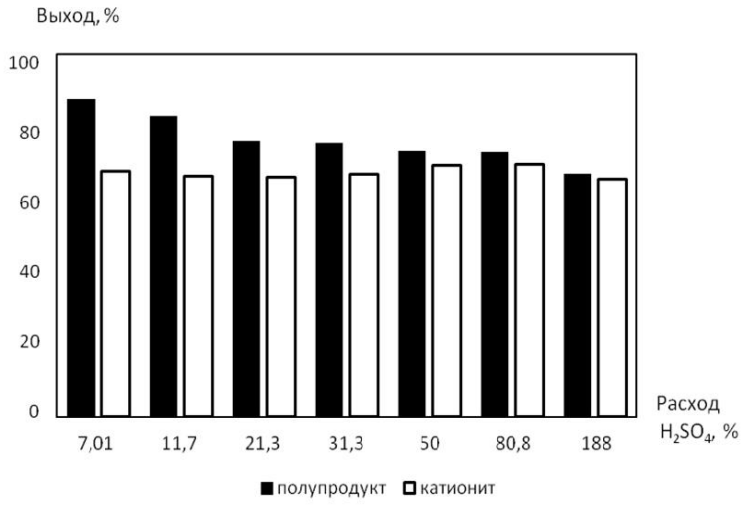

Рис. 2. Влияние расхода серной кислоты на выход продуктов

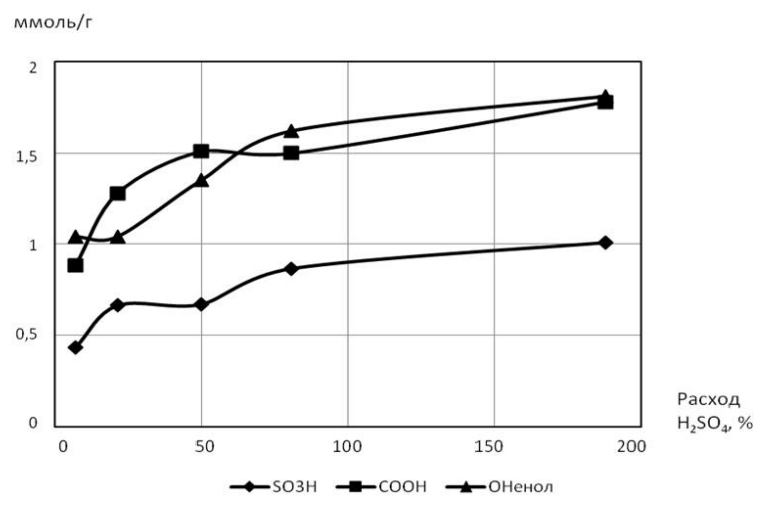

Рис. 3. Влияние расхода серной кислоты на накопление в катионитах кислотных групп 
Действительно, результаты выполненных экспериментов, представленные на рисунке 4, показывают, что полученные сорбенты имеют высокое сродство к катионам тяжелых металлов. Емкость полученных сорбентов к испытанным катионам значительно выше емкости необработанных опилок, сорбция которыми этих металлов, как было показано в специально проведенных экспериментах, не превышает 0,1 ммоль/г. При этом сорбенты в ионизированном состоянии (Na-форма) проявляют существенно более высокое сродство к катионам металлов, чем катиониты в протонированной форме. В частности, сорбция катионов кобальта, никеля и меди сорбентами в Н-форме не превышает 0,5 ммоль/г, что более чем в 3 раза ниже сорбционной емкости катионитов, находящихся в ионизированной форме.

Относительно невысокое сродство сорбентов в Н-форме к катионам тяжелых металлов можно объяснить тем, что сорбция катионов происходит за счет отщепления протонов от кислотных групп сорбентов, и это приводит к увеличению кислотности растворов. В некоторых экспериментах была измерена кислотность растворов и установлено, что рН фильтратов после выдерживания растворов нитратов металлов с катионитами в Н-форме снижается на 2-3 единицы и приобретает значения в диапазоне 1,5-3,0. Снижение $\mathrm{pH}$ растворов препятствует ионизации кислотных групп, что затрудняет их участие в образовании химических связей с катионами металлов. При использовании же катионитов в Na-форме при сорбции катионов тяжелых металлов происходит переход в раствор катионов натрия и величина рН практически не меняется, что благоприятствует взаимодействию ионогенных групп сорбента с катионами. К тому же сорбция катионов тяжелых металлов в этом случае происходит с участием не только сильнокислотных, но и слабокислотных центров сорбентов.

Влияние расхода серной кислоты, задействованной для приготовления сорбентов, на сорбционные свойства катионитов весьма значительно. Однако в наиболее сильной степени это влияние проявляется уже при включении в реакционную систему небольшого количества кислоты. В частности, при концентрации реагента в растворе, равной 4,4\% (расход 7\%), сорбционная емкость Na-формы для всех изученных катионов уже достигает значения 1,0 ммоль/г. Повышение расхода реагента до 50\% приводит к увеличению сорбционной емкости для изученных катионов до величины 1,3-1,6 ммоль/г.
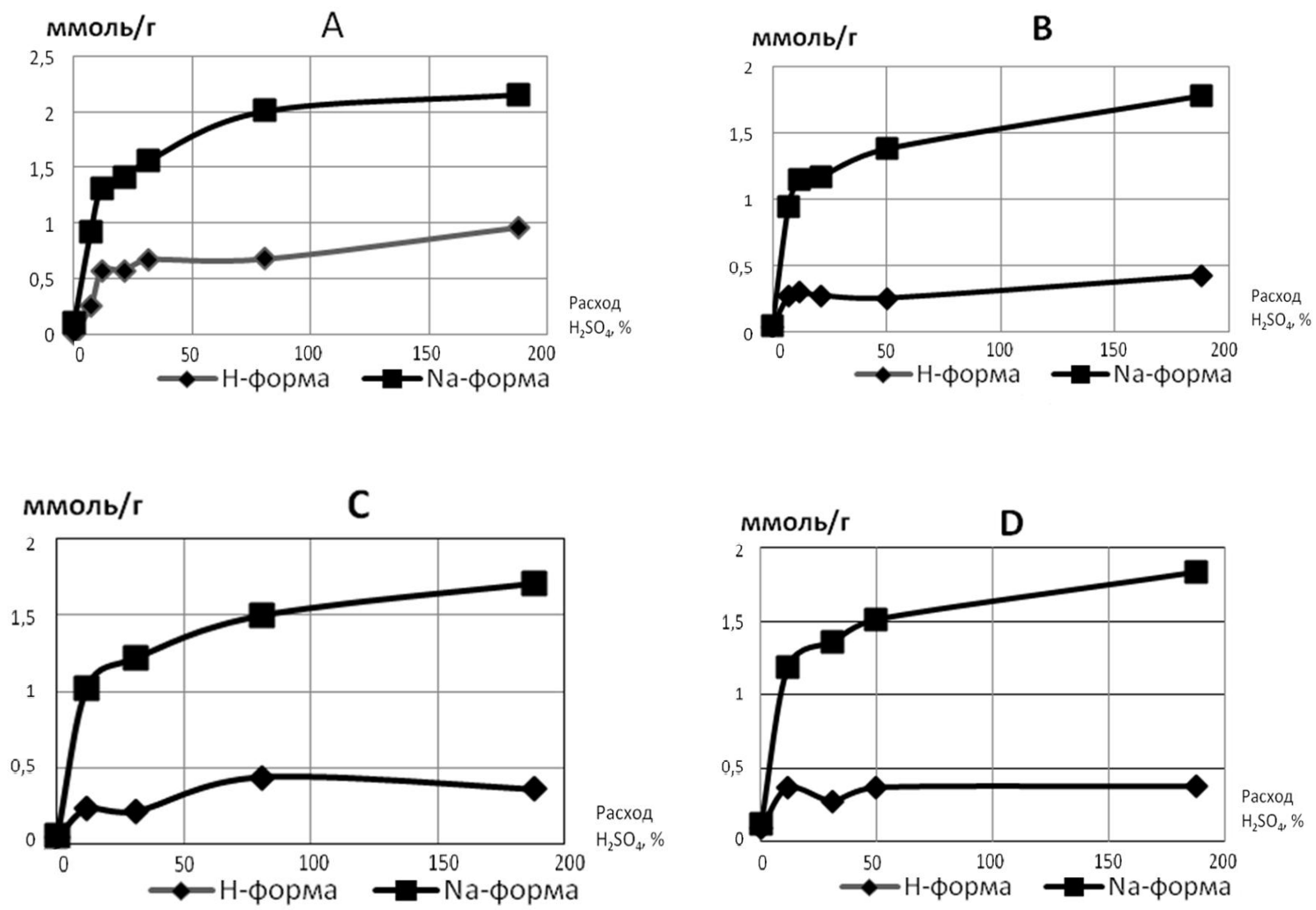

Рис. 4. Влияние расхода серной кислоты на сорбцию катионов свинца (А), кобальта (В), никеля (C) и меди (D) 
При рассмотрении экспериментальных данных обращают на себя внимание определенные отличия в сродстве получаемых сорбентов к различным катионам. Так, максимальная емкость сорбентов в ионизированном состоянии к элементам возрастает в последовательности (ммоль/г): $\mathrm{Ni}(1,71)>\mathrm{Co}(1,78)>\mathrm{Cu}$ $(1,83)>\mathrm{Pb}(2,16)$. Наблюдаемые различия в сродстве к отдельным металлам, очевидно, объясняются особенностями взаимного расположения кислотных центров в сорбентах, которые могут быть более благоприятны для взаимодействия с некоторыми катионами.

\section{Bbыводы}

1. Модифицирование еловых опилок посредством их обработки разбавленным раствором серной кислоты с удалением в ходе процесса воды позволяет получать с высоким выходом полифункциональные катиониты, содержащие сульфоновокислые, карбоксильные и енольные функциональные группы.

2. Выход катионитов в зависимости от начальной концентрации кислоты меняется незначительно и лежит в диапазоне 65,6-69,6\%; однако при низкой концентрации кислотного реагента (менее 15\%) одновременно образуется значительное количество (более 10\%) побочных, растворимых в щелочной среде продуктов.

3. Содержание ионогенных групп в катионитах увеличивается с повышением концентрации серной кислоты и при начальной концентрации кислотного реагента в реакционной смеси $56 \%$ достигает величины 4,6 ммоль/г.

4. Получаемые катиониты имеют высокое сродство к катионам тяжелых металлов, в наибольшей степени проявляющееся при использовании сорбентов в ионизированном состоянии. Максимальная емкость к элементам у сорбентов в ионизированном состоянии возрастает в последовательности (ммоль/г): $\mathrm{Ni}(1,71)>\mathrm{Co}(1,78)>\mathrm{Cu}(1,83)>\mathrm{Pb}(2,16)$.

\section{Сиисок литературы}

1. Stanley E.M. Environmental chemistry. Boca Raton, 2000. 876 p.

2. Heavy Metals in the Environment / Ed. B. Sakar. N.Y., 2002. 725 p.

3. Ion Exchange: Science and Technology / Ed. A.E. Rodriques. Dordrecht, 1986. 614 p.

4. Biosorbents for Metal Ions / Eds by J. Wase and C. Forster. London, 2003. 233 p.

5. Wan Ngah W.S., Hanafiah M.A.K.M. Removal of heavy metal ions from wastewater by chemically modified plant wastes as adsorbents: A review // Bioresource Technology. 2008. Vol. 99. Pp. 3935-3948.

6. Yenench A.M., Maitra S., Eldemerdash U. Study on Biosorption of Heavy Metals by Modified Lignocellulosic Waste // Journal of Applied Sciences. 2011. Vol. 11, N21. Pp. 3555-3562.

7. Sciban M., Kladnja M. Wood sawdust and wood originate materials as adsorbents for heavy metal ions // Holz Roh Werkst. 2004. Vol. 62. Pp. 69-73.

8. Bulut Y., Yokus B. Adsorption of heavy metal ions by popular sawdust // Cellulose Chemistry and Technology. 2007. Vol. 41. Pp. 7-8, 443-450.

9. Азаров В.И., Буров А.В., Оболенская А.В. Химия древесины и синтетических полимеров. СПб., 1999. 628 с.

10. Huang L., Ou Z., Boving T. B., Tyson J., Xing B. Sorption of copper by chemically modified aspen wood fibers // Chemosphere. 2009. Vol. 76. Pp. 1056-1061.

11. Su P., Granholm K., Pranovich A., Harju L., Holmbom B., Ivaska A. Sorption of metal ions to untreated, alkalitreated and peroxide-bleached TMP // Cellulose. 2010. Vol. 17. Pp. 1033-1044.

12. Крайнова Е.А., Родионов А.И., Ким А.В. Получение углеродного сульфокатионита методом сернокислотного обугливания целлюлозосодержащих отходов // Экология и промышленность России. 2008. №3. С. 21-23.

13. Дейнеко И.П., Хакало А.С., Пранович А.В. Получение катионообменных сорбентов обработкой еловых опилок серной кислотой // Химия растительного сырья. 2011. №4. С. 33-38.

14. Дейнеко И.П. Получение катионообменных сорбентов из древесных опилок // Известия Санкт-Петербургской лесотехнической академии. 2013. Вып. 202. С. 178-187.

15. Дейнеко И.П., Симонова А.Н. Приготовление катионитов обработкой древесных опилок водным раствором серной кислоты при пониженном давлении // Известия Санкт-Петербургской лесотехнической академии. 2014. Вып. 208. С. 184-192.

16. Салдадзе К.М., Копылова-Валова В.Д. Комплексообразующие иониты (комплекситы). М., 1980. 336 с.

17. Шварценбах Г., Флашка Г. Комплексонометрическое титрование : пер. с нем. М., 1970. 360 с.

18. Шарло Г. Методы аналитической химии. М., 1969. 1204 с. 
Deineko I.P. , Simonova A.N. SORPTION PROPERTIES OF CATION EXCHANGERS OBTAINED BY TREATMENT OF SPRUCE SAWDUST WITH SULFURIC ACID SOLUTION

St. Petersburg State Technological University of Plant Polymers, Ivana Chernykh st., 4, St. Petersburg, 198095

(Russia),e-mail: ipdeineko@mail.ru

A process for producing cation exchangers from wood materials, comprising a heat treatment under vacuum sawdust impregnated with an aqueous solution of sulfuric acid, with simultaneous distillation of the excess and reaction water is proposed. The target product (yield $-66-68 \%$ ) is polyfunctional cation exchangers containing strongly and weakly acid groups. The influence of the concentration of sulfuric acid used for impregnation of sawdust in the range of 4,4-56,0\% on ion-exchange properties of the resulting cation exchangers is studied. The content of acid groups in the cation exchangers with increasing concentration of acid increases, and at a concentration of $56 \%$ reaches value $4.6 \mathrm{mmol} / \mathrm{g}$. The sorption of cation heavy metal ions is studied. The maximum capacity for the elements of the sorbents in ionized form increases in the sequence $(\mathrm{mmol} / \mathrm{g}): \mathrm{Ni}$ $(1,71)>\mathrm{Co}(1,78)>\mathrm{Cu}(1,83)>\mathrm{Pb}(2,16)$.

Keywords: Spruce sawdust, sulfuric acid, cation exchangers, exchange capacity, acid groups, sorption, lead, cobalt, nickel, copper.

\section{References}

1. Stanley E.M. Environmental chemistry. Boca Raton, 2000, 876 p.

2. Heavy Metals in the Environment. Ed. B. Sakar, N.Y., 2002, 725 p.

3. Ion Exchange: Science and Technology. Ed. A.E. Rodriques. Dordrecht, 1986. 614 p.

4. Biosorbents for Metal Ions. Eds by J. Wase and C. Forster. London, 2003, 233 p.

5. Wan Ngah W.S., Hanafiah M.A.K.M. Bioresource Technology, 2008, vol. 99, pp. 3935-3948.

6. Yenench A.M., Maitra S., Eldemerdash U. Journal of Applied Sciences, 2011, vol. 11, no. 21, pp. 3555-3562.

7. Sciban M., Kladnja M. Holz Roh Werkst., 2004, vol. 62, pp. 69-73.

8. Bulut Y., Yokus B. Cellulose Chemistry and Technology, 2007, vol. 41, pp. 7-8, 443-450.

9. Azarov V.I., Burov A.V., Obolenskaia A.V. Khimiia drevesiny i sinteticheskikh polimerov. [Wood Chemistry and synthetic polymers]. St. Petersburg, 1999, 628 p. (in Russ.).

10. Huang L., Ou Z., Boving T. B., Tyson J., Xing B. Chemosphere, 2009, vol. 76, pp. 1056-1061.

11. Su P., Granholm K., Pranovich A., Harju L., Holmbom B., Ivaska A. Cellulose, 2010, vol. 17, pp. 1033-1044.

12. Krainova E.A., Rodionov A.I., Kim A.V. Ekologiia i promyshlennost' Rossii, 2008, no. 3, pp. 21-23. (in Russ.).

13. Deineko I.P., Khakalo A.S., Pranovich A.V. Khimiia rastitel'nogo syr'ia, 2011, no. 4, pp. 33-38. (in Russ.).

14. Deineko I.P. Izvestiia Sankt-Peterburgskoi lesotekhnicheskoi akademii, 2013, issue 202, pp. 178-187. (in Russ.).

15. Deineko I.P., Simonova A.N. Izvestiia Sankt-Peterburgskoi lesotekhnicheskoi akademii, 2014, issue 208, pp. 184-192. (in Russ.).

16. Saldadze K.M., Kopylova-Valova V.D. Kompleksoobrazuiushchie ionity (kompleksity). [Complexing ion exchangers (complexes)]. Moscow, 1980, 336 p. (in Russ.).

17. Shvartsenbakh G., Flashka G. Kompleksonometricheskoe titrovanie. [Complexometric titration]. Moscow, 1970, 360 p. (in Russ.).

18. Sharlo G. Metody analiticheskoi khimii. [Methods of analytical chemistry]. Moscow, 1969, 1204 p. (in Russ.).

Received February 27, 2015

Revised Juny 18, 2015

\footnotetext{
"Corresponding author.
} 